\title{
SEOUL NATIONAL UNIVERSITY ACCELERATOR MASS SPECTROMETRY (SNU-AMS) RADIOCARBON DATE LIST II
}

\author{
J C Kim, M Y Youn, I C Kim, J H Park, Y M Song, J Kang \\ Inter-University Center for Natural Science Research Facility, Building 139-1, Seoul National University, Seoul 151-742, \\ Korea.
}

\section{K Cheoun}

Department of Physics, Soongsil University, Dongjak-Gu, Seoul 156-743, Korea.

Corresponding author. Email: cheoun@ssu.ac.kr.

\section{INTRODUCTION}

The accelerator mass spectrometry facility at Seoul National University (SNU-AMS) began functioning in December 1998 and was first reported at the Vienna AMS conference in October 1999 and at the 17th Radiocarbon Conference in Israel in June 2000. At the Vienna conference, we reported our accelerator system (Kim et al. 2000) and the basic sample preparation system (Lee et al. 2000), including the combustion line to produce $\mathrm{CO}_{2}$; the catalytic reduction line for the graphitization of $\mathrm{CO}_{2}$; and also pretreatment procedures for wood, charcoal, and peat samples. Recent progress of the AMS facility (Kim et al. 2001) and extension of the sample pretreatment system to iron and bone samples were reported at the 17th Radiocarbon Conference (Cheoun et al. 2001). In the meantime, extensive testing of accuracy and reproducibility has been carried out, and $~ 1000$ unknown archaeological and geological samples have been measured every year. A report of data carried out in 1999 is presented by Kim et al. (this issue). In this report, the archaeological, geological, and environmental data carried out in 2000 are presented in terms of yr BP.

\section{ARCHAEOLOGICAL SAMPLES}

\section{Seomyun Series}

Seomyun ( $\left.37^{\circ} 55^{\prime} 42^{\prime \prime} \mathrm{N}, 127^{\circ} 43^{\prime} 21^{\prime \prime} \mathrm{E}\right)$, Chuncheon-si, Gangwon-do, is an archaeological site under a modern bridge. Expected ages are Bronze Age (about 4th century BC). Samples are charcoals submitted in 2000 by Hanlym University.

\section{SNU00-01. F.14}

$2060 \pm 50$

SNU00-01-2. F.14

$1900 \pm 70$

From the 14th ancient dwelling. The latter sample was accelerated with no combustion after pretreatment in order to compare both procedures.

SNU00-02. F.17

$3200 \pm 50$

SNU00-02-2. F.17

$2690 \pm 60$

From the 17th ancient dwelling. The latter sample was accelerated with no combustion after pretreatment in order to compare both procedures.

SNU00-03. F18

From the 18th ancient dwelling.

SNU00-04. F27

From the 27th ancient dwelling. Expected ages of the above samples (from SNU00-01 to -04) are presumed to be Bronze Age. 
SNU00-05-1. F7

$2040 \pm 40$

SNU00-05-2. F7

$1910 \pm 50$

From the 7th ancient dwelling. Both samples above are different samples taken from the same site.

SNU00-06. F20

$1940 \pm 40$

From the 20th ancient dwelling.

SNU00-07. samcheon-dong1

$1800 \pm 40$

From the 1st ancient dwelling at Samcheon-dong $\left(37^{\circ} 01^{\prime} 42^{\prime \prime} \mathrm{N}, 127^{\circ} 41^{\prime} 49^{\prime \prime} \mathrm{E}\right)$.

SNU00-08. junggum-ri1

$1870 \pm 40$

From the 1st ancient dwelling at Junggum-ri near Hwengseng Dam.

SNU00-09. junggum-ri2

$2790 \pm 40$

From the 2nd ancient dwelling at Junggum-ri near Hwengseng Dam.

SNU00-10. junggum-ri3

From the 3rd ancient dwelling at Junggum-ri $\left(37^{\circ} 32^{\prime} 50^{\prime \prime} \mathrm{N}, 128^{\circ} 03^{\prime} 00^{\prime \prime} \mathrm{E}\right)$ near Hwengseng Dam. Expected ages of the above samples (from SNU00-06 to -10) are Iron Age.

Buyeo Series

Buyeo is the site of an ancient capital and was investigated by the Buyeo Institute of Cultural Properties. Samples are charcoals and wood and were submitted in 1998 by Gyonyun Kim.

SNU00-11. S1

$1940 \pm 50$

SNU00-12. S2

$1450 \pm 30$

SNU00-13. S3

$1860 \pm 30$

SNU00-14. S4

$1300 \pm 40$

SNU00-15. S5

$2100 \pm 30$

The above samples are wood.

SNU00-16. S6

$1510 \pm 50$

SNU00-17. S7

$1730 \pm 60$

SNU00-18. $S 8$

$1660 \pm 70$

SNU00-19. S9

$1500 \pm 30$

SNU00-20. S10

$1520 \pm 80$

The above samples are charcoals. The samples (SNU00-11 to -20) were from Kungnamji 3-1, Dongnam-ri $\left(36^{\circ} 16^{\prime} 30^{\prime \prime} \mathrm{N}, 126^{\circ} 54^{\prime} 21^{\prime \prime} \mathrm{E}\right)$.

SNU00-21. S11

$1740 \pm 40$

SNU00-22. S12

$1410 \pm 30$

SNU00-23. S13

$1640 \pm 40$

The above samples are charcoals from the mountain fortress Buso-sanseng $\left(36^{\circ} 17^{\prime} \mathrm{N}, 126^{\circ} 55^{\prime} \mathrm{N}\right)$ in Buyeo. 
Silsang Series

Silsang-sa $\left(35^{\circ} 24^{\prime} 48^{\prime \prime} \mathrm{N}, 127^{\circ} 38^{\prime} 18^{\prime \prime} \mathrm{E}\right)$ is an old temple in Namweon-si, Jeonnam-do, and was investigated by the Buyeo Institute of Cultural Properties. Samples are charcoals and were submitted in 1998 by Gyonyun Kim.

SNU00-24. S14

$1370 \pm 30$

SNU00-25. S15

$1840 \pm 40$

SNU00-26. S16

$1080 \pm 40$

SNU00-27. S17

$1160 \pm 40$

SNU00-28. S18

$1350 \pm 80$

SNU00-29. S19

$1730 \pm 50$

SNU00-30. S20

$2950 \pm 60$

This sample is terribly contaminated by soil attached to the charcoal.

Youngnam Series

The Youngnam site $\left(36^{\circ} 05^{\prime} 30^{\prime \prime} \mathrm{N}, 129^{\circ} 20^{\prime} 30^{\prime \prime} \mathrm{E}\right)$, Gyeongnam-do, was investigated by Yongha Kim at the Youngnam Institute of Cultural Properties. Samples are charcoals found at $21.8 \mathrm{~m}$ and are presumed to be Bronze Age.

SNU00-31. PC-6

$3300 \pm 50$

SNU00-32. PC-12

$3060 \pm 40$

Ogbang Series

The Ogbang site $\left(35^{\circ} 13^{\prime} 12^{\prime \prime} \mathrm{N}, 127^{\circ} 57^{\prime} 49^{\prime \prime} \mathrm{E}\right)$, Daepyung-ri, Gyeongnam-do, was investigated by Dongwui University. The samples are charcoals submitted in 2000 by Hyotaek Lim at SNU.

SNU00-44-1. Dongi 1

$3280 \pm 50$

From the 21st ancient dwelling at Okbang section 4.

SNU00-44-2. Dongi 1

$2880 \pm 40$

From the 21st ancient dwelling at Okbang section 4.

SNU00-45. Dongi 2

$4470 \pm 40$

From the 27th ancient dwelling at Okbang section 4.

SNU00-46. Dongi 3

$2730 \pm 40$

From the 65th ancient dwelling at Okbang section 4.

SNU00-47. Dongi 4

$2750 \pm 30$

From the 5th archaeological yard at Okbang section 4.

SNU00-48. Dongi 5

$4290 \pm 30$

Samples are charcoals from the 4th hole at a dolmen and a deposit with pottery fragments at Sangchon-ri $\left(35^{\circ} 12^{\prime} 50^{\prime \prime} \mathrm{N}, 127^{\circ} 58^{\prime} 00^{\prime \prime} \mathrm{E}\right)$. 
Kimhae Series

The Kimhae site ( $\left.35^{\circ} 15^{\prime} 06^{\prime \prime} \mathrm{N}, 128^{\circ} 52^{\prime} 36^{\prime \prime} \mathrm{E}\right)$, Kusan-dong, Kimhae-si, Gyeongnam-do, was investigated by Dongwui University. Samples are charcoals and were submitted in 2000 by Hyotaek Lim at SNU.

SNU00-49. Dongi 6-4

$2490 \pm 40$

From the 4th ancient dwelling.

SNU00-50. Dongi 7

$1580 \pm 30$

From the 3rd archaeological site.

SNU00-51. Dongi 8

$1570 \pm 40$

From archaeological site B.

Buan Series

The Buan site $\left(35^{\circ} 35^{\prime} 18^{\prime \prime} \mathrm{N}, 126^{\circ} 41^{\prime} 30^{\prime \prime} \mathrm{E}\right)$, Jangdong-ri, Julpo-myun, Buan-gun, Jeonbuk-do, was investigated in 2000 by Sungok Kim at Jeonbuk University. Samples are charcoals.

SNU00-52. 1

$1930 \pm 70$

From the 1st ancient dwelling.

SNU00-53. 2

$1820 \pm 50$

From the 4th ancient dwelling.

SNU00-54. 3

$1860 \pm 60$

From the 5th ancient dwelling.

SNU00-55. 4

$2130 \pm 40$

From the 9th ancient dwelling.

SNU00-56. 5

$1780 \pm 60$

From the 11th ancient dwelling.

SNU00-57. 6

$2050 \pm 40$

From the 12th ancient dwelling.

SNU00-58. 7

$2030 \pm 40$

From the 17th ancient dwelling.

SNU00-59. 8

$2110 \pm 40$

From the 20th ancient dwelling.

SNU00-60. 9

$1750 \pm 60$

From the 22nd ancient dwelling.

SNU00-61. 10

$1820 \pm 40$

From the 29th ancient dwelling.

SNU00-62. 11

$2680 \pm 40$

From the 6th archaeological site at Haribsuk-ri, Boan-muyn $\left(35^{\circ} 37^{\prime} 12^{\prime \prime} \mathrm{N}, 126^{\circ} 43^{\prime} 18^{\prime \prime} \mathrm{E}\right)$. 
Koheung Series

Koheung $\left(34^{\circ} 48^{\prime} 54^{\prime \prime} \mathrm{N}, 127^{\circ} 20^{\prime} 18^{\prime \prime} \mathrm{E}\right)$, Hancheon-ri, Jeonnam-do, is a site of ancient dwellings. Samples are charcoals and were submitted in 2000 by Yeongmun Lee at Mokpo University.

SNU00-70. Koheung 1

$2050 \pm 50$

From an ancient stone fortress.

SNU00-71. Koheung 2

$1830 \pm 60$

From a pot grave.

Hwasun Series

The Hwasun site ( $\left.34^{\circ} 57^{\prime} 42^{\prime \prime} \mathrm{N}, 126^{\circ} 56^{\prime} 30^{\prime \prime} \mathrm{E}\right)$, Daesin-ri, Jeonnam-do, is an ancient tomb. Samples are charcoals collected from the 27th stone room and were submitted in 2000 by Yeongmun Lee.

SNU00-72. Hwasun 1

$2500 \pm 80$

SNU00-73. Hwasun 2

$300 \pm 50$

SNU00-74. Hwasun 3

$1950 \pm 50$

Yeosu Series

The Yeosu site $\left(34^{\circ} 46^{\prime} 30^{\prime \prime} \mathrm{N}, 127^{\circ} 38^{\prime} 48^{\prime \prime} \mathrm{E}\right)$, Hwajang-dong, Jeonnam-do, is a dolmen. Samples are charcoals collected from the stone chamber within the dolmen and were submitted in 2000 by Yeongmun Lee.

SNU00-75. Yeosu 1

$2630 \pm 40$

SNU00-76. Yeosu 2

$2730 \pm 40$

Dongsamdong Series

The Dongsamdong site $\left(35^{\circ} 03^{\prime} 42^{\prime \prime} \mathrm{N}, 129^{\circ} 04^{\prime} 54^{\prime \prime} \mathrm{E}\right)$, Busan-si, is an ancient shell tomb investigated in 1969. Samples are bones submitted in 2000 by Seyeon Oh, and the expected ages are Neolithic.

SNU00-86-1. D1

$3800 \pm 60$

At IV 2-2 (III culture layer) at $0.4 \mathrm{~m}$ depth.

SNU00-87. D2

$4360 \pm 40$

At IV 3-5 (II culture layer) at $1.0 \mathrm{~m}$ depth.

SNU00-88. D3

$4300 \pm 40$

At IV 3-10 (I culture layer) at $1.4 \mathrm{~m}$ depth.

SNU00-89. D4

$4650 \pm 50$

At FV 2-3 (III culture layer) at $0.2 \mathrm{~m}$ depth.

SNU00-90. D5

$5800 \pm 70$

At FV 3-4 (II culture layer) at $0.6 \mathrm{~m}$ depth.

SNU00-91. D6

$5580 \pm 70$

At FV 4 (I culture layer) at $1.0 \mathrm{~m}$ depth.

SNU00-92. D7

$6400 \pm 50$

At DXIX 3 at $0.7 \mathrm{~m}$ depth. 
SNU00-93. D8

$4200 \pm 40$

At HXIII 2 at $0.7 \mathrm{~m}$ depth.

$4600 \pm 100$

SNU00-94. D9

At HXIII 3 at $1.1 \mathrm{~m}$ depth.

Kyodong Series

The Kyodong site, Kangreung-si, Gangwon-do $\left(37^{\circ} 45^{\prime} 54^{\prime \prime} \mathrm{N}, 128^{\circ} 53^{\prime} 54^{\prime \prime} \mathrm{E}\right)$, is an ancient dwelling expected to be of the Bronze Age. The site was investigated in 1997. Samples are charcoals submitted in 2000 by Kangneung University.

SNU00-95. No1

$2880 \pm 40$

At the 2nd dwelling.

SNU00-96. No2

$2980 \pm 60$

At the 1st dwelling.

SNU00-97. No3

$2980 \pm 40$

At the 3rd dwelling.

Cheonmachong Series

The Cheonmachong site $\left(35^{\circ} 49^{\prime} 21^{\prime \prime} \mathrm{N}, 129^{\circ} 14^{\prime} 24^{\prime \prime} \mathrm{E}\right)$, Kyungju-si, is an ancient tomb investigated in 1999. Samples are textiles and wood found inside the tomb and were submitted in 2000 by Yeunsuk Lee.

SNU00-119. No6

$1730 \pm 40$

A textile sample.

SNU00-118. No5

$1570 \pm 40$

A wood sample.

SNU00-117. No4

$1530 \pm 40$

A textile sample.

SNU00-114. No2

$1550 \pm 90$

A wood sample found on the husband's saddle.

Pungnab Series

Pungnab site $\left(37^{\circ} 31^{\prime} 10^{\prime \prime} \mathrm{N}, 127^{\circ} 07^{\prime} \mathrm{E}\right)$, Seoul, was investigated in 1999. Samples are charcoals submitted in 2000 by Oyong Kwon and Youngbae Sung.

SNU00-120. Pungnab 1

$1520 \pm 40$

At the west side of the 44th dwelling.

SNU00-121. Pungnab 2

$1680 \pm 40$

At the east side of the 44th dwelling.

SNU00-201. A-1

$1750 \pm 80$

SNU00-202. A-3

$1680 \pm 50$

SNU00-226. Pungnab 79E

$1780 \pm 40$

SNU00-227. Pungnab 79W

$1900 \pm 60$ 
Yeonmu Series

The Yeonmu site $\left(36^{\circ} 05^{\prime} 42^{\prime \prime} \mathrm{N}, 127^{\circ} 05^{\prime} 00^{\prime \prime} \mathrm{E}\right)$ is located in Majeon-ri, Yeonmu-ub, Nonsan-si, Chungnam-do. Samples are charcoals and wood submitted in 2000 by Korea University.

SNU00-145. \#1

SNU00-146. \#2

SNU00-148. \#4

SNU00-149. \#5

SNU00-150. \#6

SNU00-151. \#7

SNU00-152. \#8

SNU00-153. \#9

SNU00-154. \#10

SNU00-155. \#11

SNU00-156. \#12

SNU00-157. \#13

SNU00-159. \#15

SNU00-160. \#16

SNU00-161. \#17

SNU00-162. \#18

SNU00-163. \#19

SNU00-164. \#20

The above sam were collected from section A.

SNU00-165. \#21

SNU00-166. \#22

SNU00-167. \#23

SNU00-168. \#24

SNU00-169. \#25

SNU00-170. \#26

SNU00-171. \#27

SNU00-172. \#28

SNU00-173. \#29

The above samples are wood.
$2620 \pm 40$

$1920 \pm 40$

$2350 \pm 120$

$1470 \pm 60$

$1520 \pm 40$

$1570 \pm 50$

$1750 \pm 50$

$1340 \pm 40$

$1550 \pm 40$

$1850 \pm 80$

$1800 \pm 80$

$1730 \pm 70$

$2640 \pm 200$

$2540 \pm 40$

$2410 \pm 40$

$2360 \pm 150$

$2380 \pm 80$

$2560 \pm 40$
$2560 \pm 40$

$1910 \pm 30$

$1570 \pm 40$

$2820 \pm 80$

$2820 \pm 100$

$2470 \pm 60$

$2770 \pm 60$

$2780 \pm 40$

$2790 \pm 60$ 
Jugyo Series

The Jugyo site $\left(36^{\circ} 22^{\prime} 12^{\prime \prime} \mathrm{N}, 126^{\circ} 33^{\prime} 00^{\prime \prime} \mathrm{E}\right)$ is located in Jugyo-ri, Boryung-gun, Chungnam-do. Samples are charcoals.

SNU00-176. \#32

$2510 \pm 90$

SNU00-177. \#33

$2770 \pm 40$

SNU00-178. \#34

$2850 \pm 80$

SNU00-179. \#35

$6650 \pm 40$

SNU00-180. \#36

$2840 \pm 40$

SNU00-181. \#37

$2620 \pm 40$

\section{Hwangtan Series}

The Hwangtan site $\left(36^{\circ} 35^{\prime} 36^{\prime \prime} \mathrm{N}, 127^{\circ} 20^{\prime} 49^{\prime \prime} \mathrm{E}\right)$ is located in Kangnae-myun, Chengwon-gun, Chungnam-do. Samples are charcoals.

SNU00-183. \#39

$2420 \pm 30$

SNU00-184. \#40

$2750 \pm 40$

SNU00-185. \#41

$2470 \pm 50$

SNU00-187. \#43

$2500 \pm 50$

\section{Seogkok Series}

The Seogkok site $\left(36^{\circ} 44^{\prime} 06^{\prime \prime} \mathrm{N}, 127^{\circ} 13^{\prime} 36^{\prime \prime} \mathrm{E}\right)$ is located in Seogkok-myun, Cheon-si, Chungnamdo. Samples are charcoals.

SNU00-188. \#44

$2650 \pm 50$

SNU00-189. \#45

$2520 \pm 40$

SNU00-190. \#46

$2490 \pm 40$

SNU00-191. \#47

$2480 \pm 60$

SNU00-192. \#48

$2420 \pm 80$

SNU00-193. \#49

$2480 \pm 60$

SNU00-194. \#50

$2440 \pm 50$

Noeun Series

Noeun site $\left(36^{\circ} 21^{\prime} 54^{\prime \prime} \mathrm{N}, 127^{\circ} 18^{\prime} 42^{\prime \prime} \mathrm{E}\right)$ is found in Yuseng-gu, Daejun-si, Chungnam-do. Samples are charcoals.

SNU00-195. \#51

$2660 \pm 40$

SNU00-196. \#52

$3000 \pm 70$

SNU00-197. \#53

$2930 \pm 50$

SNU00-198. \#54

$1590 \pm 50$

From Yonji-ri (36 $\left.24^{\prime} 06^{\prime \prime} \mathrm{N}, 126^{\circ} 33^{\prime} 54^{\prime \prime} \mathrm{E}\right)$, Jupo-myun, Boryung-si, Cheungnam-do. 


\section{Sunchon Series}

The Sunchon site $\left(35^{\circ} 10^{\prime} 50^{\prime \prime} \mathrm{N}, 126^{\circ} 38^{\prime} 40^{\prime \prime} \mathrm{E}\right)$ is in Wolya-myun, Hampyung-gun. Samples are wood submitted in 2000 by Sengrak Choi. Expected ages are AD 2nd to 3rd century.

SNU00-199. A

$1660 \pm 50$

SNU00-200. B

$1700 \pm 60$

\section{Gochang Series}

Sengnam-ri $\left(35^{\circ} 22^{\prime} 24^{\prime \prime} \mathrm{N}, 126^{\circ} 35^{\prime} 42^{\prime \prime} \mathrm{E}\right)$ is located in Gochang-gun, Jeonbuk-do. Samples are charcoals submitted in 2000 by Wongwang University.

SNU00-228. VA-1

$1890 \pm 80$

From the 1st archaeological site.

SNU00-229. VA-2

$1690 \pm 60$

From the 2nd archaeological site.

SNU00-230. VA-3

$1580 \pm 80$

From the 3rd archaeological site.

SNU00-231. VA-4

$1570 \pm 50$

From the 4th archaeological site.

SNU00-232. VA-5

$1680 \pm 80$

From the 5th archaeological site.

SNU00-233. VA-63

$1590 \pm 80$

From the 6th archaeological site.

SNU00-234. san-7

$1860 \pm 40$

From the 7th archaeological site at Sangeung-ri $\left(35^{\circ} 20^{\prime} 00^{\prime \prime} \mathrm{N}, 126^{\circ} 35^{\prime} 18^{\prime \prime} \mathrm{E}\right)$.

SNU00-235. san-8

$2350 \pm 40$

From the 8th archaeological site at Sangeung-ri.

SNU00-236. sin-9

$1610 \pm 50$

From the 9th archaeological site at Sindugg-ri $\left(35^{\circ} 33^{\prime} 30^{\prime \prime} \mathrm{N}, 126^{\circ} 40^{\prime} 18^{\prime \prime} \mathrm{E}\right)$.

SNU00-237. $\sin -10$

$1900 \pm 100$

From the 10th archaeological site at Sindugg-ri.

SNU00-238. sinsong-11

$1600 \pm 50$

From the 11th archaeological site at Sinsong-ri $\left(35^{\circ} 32^{\prime} 24^{\prime \prime} \mathrm{N}, 126^{\circ} 42^{\prime} 00^{\prime \prime} \mathrm{E}\right)$.

Iksan Series

The Iksan site $\left(35^{\circ} 56^{\prime} 48^{\prime \prime} \mathrm{N}, 126^{\circ} 56^{\prime} 48^{\prime \prime} \mathrm{E}\right)$ is in Jeonbuk-do. Samples are charcoals submitted in 2000 by Wongwang University.

SNU00-239. igsan-12

$1760 \pm 70$

From the 12th archaeological site.

SNU00-240. igsan-13

$1890 \pm 70$

From the 13th archaeological site. 
SNU00-241. igsan-14

$1840 \pm 60$

From the 14th archaeological site.

SNU00-242. igsan-15

$1770 \pm 40$

From the 15th archaeological site.

\section{Daemok Series}

Daemok-ri $\left(35^{\circ} 48^{\prime} 54^{\prime \prime} \mathrm{N}, 126^{\circ} 50^{\prime} 49^{\prime \prime} \mathrm{E}\right)$ is located in Kimje-si, Jeonbuk-do. Samples are charcoals submitted in 2000 by Jihyun Jang at Jeonbuk University. Expected ages are AD 1st to 4th century.

SNU00-246. dae-1

$1820 \pm 70$

From the 1st dwelling.

SNU00-247. dae-2

$1840 \pm 40$

From the 2nd dwelling.

SNU00-248. dae-3

$1650 \pm 40$

From the 3rd dwelling.

SNU00-249. dae-4

$1670 \pm 40$

From the 4th dwelling.

SNU00-250. dae-5

$2880 \pm 70$

From the 5th dwelling.

SNU00-251. dae-6

$2330 \pm 100$

From a hole near the 5th dwelling.

SNU00-252. dae-7

$1850 \pm 40$

From the 6th dwelling.

SNU00-253. dae-8

$1750 \pm 40$

From the square spot.

Songrim Series

The Songrim site $\left(37^{\circ} 51^{\prime} 12^{\prime \prime} \mathrm{N}, 128^{\circ} 50^{\prime} 18^{\prime \prime} \mathrm{E}\right)$ is in Jumunjin-si, Gangwon-do. Samples are charcoals submitted in 2000 by Hanrim University.

SNU00-254. s-5

$2460 \pm 30$

SNU00-255. s-12

$2850 \pm 60$

Yongho Series

The Yongho site $\left(36^{\circ} 26^{\prime} 12^{\prime \prime} \mathrm{N}, 127^{\circ} 27^{\prime} 18^{\prime \prime} \mathrm{E}\right)$ in Yongho-dong, Daejun-si, Chungnam-do, is an ancient Paleolithic dwelling. Samples are charcoals submitted in 2000 by Changgyun Han of Hannam University.

SNU00-259. HN-1

$4200 \pm 100$

From the 1st cultural layer.

SNU00-260. HN-2

$700 \pm 100$

From the 2nd cultural layer. 
SNU00-261. HN-3

$\mathbf{3 8 , 5 0 0} \pm \mathbf{1 0 0 0}$

From the 3rd cultural layer.

SNU00-262. HN-4

$33,500(+10,000 /-1000)$

From the 4th cultural layer.

$4400 \pm 60$

SNU00-263. HN-5

From an ancient dwelling ( $\left.36^{\circ} 16^{\prime} 48^{\prime \prime} \mathrm{N}, 127^{\circ} 34^{\prime} 12^{\prime \prime} \mathrm{E}\right)$ in Daechun-ri, Okchun-gun, Chungnam-do. The expected age is Neolithic.

\section{Taeku Series}

Samples are charcoals submitted in 2000 by Yonghi Kim of the Yeongnam Institute of Cultural Properties.

SNU00-265. TC1

$2570 \pm 40$

From the 20th archaeological site, Dongcheon-dong ( $\left.35^{\circ} 56^{\prime} 30^{\prime \prime} \mathrm{N}, 128^{\circ} 33^{\prime} 21^{\prime \prime} \mathrm{E}\right)$. The expected age is 5 th to 7 th century $\mathrm{BC}$, Bronze Age.

SNU00-266. TC2

$2650 \pm 200$

From the 50th archaeological site, Dongcheon-dong.

SNU00-267. TS1

$2920 \pm 60$

From the 1st archaeological site, Seobyun-dong $\left(35^{\circ} 55^{\prime} 06^{\prime \prime} \mathrm{N}, 128^{\circ} 35^{\prime} 42^{\prime \prime} \mathrm{E}\right)$. Expected age is 9 th to 10th century BC, Bronze Age.

SNU00-268. TS5

$2970 \pm 50$

From the 27th archaeological site, Seobyun-dong.

SNU00-269. TS6

$3010 \pm 60$

From the 27th archaeological site, Seobyun-dong.

SNU00-270. TS8

$2690 \pm 40$

From the 32nd archaeological site, Seobyun-dong. Expected age is 6th-7th century BC, Bronze Age.

SNU00-271. TS11

$3010 \pm 100$

From the 22nd site, Seobyun-dong. Expected age is 20th century BC, Neolithic.

SNU00-272. TS13

$2900 \pm 60$

From the 1st archaeological site, Seobyun-dong.

SNU00-274. TP2

$3190 \pm 40$

From the 14th dwelling, Paldal-dong $\left(35^{\circ} 54^{\prime} 18^{\prime \prime} \mathrm{N}, 128^{\circ} 32^{\prime} 18^{\prime \prime} \mathrm{E}\right)$. Expected age is 20 th century BC, Neolithic.

\section{Kimcheon Series}

The Kimcheon site $\left(36^{\circ} 07^{\prime} 31^{\prime \prime} \mathrm{N}, 128^{\circ} 07^{\prime} 28^{\prime \prime} \mathrm{E}\right)$ is in Moam-dong, Kimcheon-si, Gyeongbuk-do. Samples are charcoals with expected ages of AD 4th century.

SNU00-275. GM1

$1980 \pm 40$

From 7th ancient dwelling.

SNU00-276. GM2

$2020 \pm 60$

From 11th ancient dwelling. 
SNU00-278. GM4

$2080 \pm 100$

From 30th ancient dwelling.

Yeosu Series

The Yeosu site $\left(34^{\circ} 46^{\prime} 30^{\prime \prime} \mathrm{N}, 127^{\circ} 38^{\prime} 48^{\prime \prime} \mathrm{E}\right)$ is in Hwajang-dong, Yeosu-si, Jeonnam-do. Samples are charcoals submitted in 2000 by Yonsuk Yu, Suncheon University. The expected ages are AD 3rd4th century.

SNU00-279. sun1

$1670 \pm 60$

From the 25th ancient dwelling.

SNU00-280. $\operatorname{sun} 2$

$2580 \pm 40$

From the 9th ancient dwelling.

SNU00-281. $\operatorname{sun} 3$

$2150 \pm 60$

From the 12th ancient dwelling.

SNU00-282. $\operatorname{sun} 4$

$1760 \pm 30$

From the 15th ancient dwelling.

SNU00-283. sun5

$1800 \pm 40$

From the 15th ancient dwelling.

SNU00-284. sun6

$1680 \pm 40$

From the 11th ancient dwelling.

SNU00-285. $\operatorname{sun} 7$

$1990 \pm 50$

From the 23rd ancient dwelling.

SNU00-286. $\operatorname{sun} 8$

$2550 \pm 30$

From the 9th ancient dwelling.

SNU00-287. sun9

$1690 \pm 40$

From the 2nd ancient dwelling.

SNU00-288. sun10

$2150 \pm 30$

From the 3rd ancient dwelling.

SNU00-289. sun11

$1640 \pm 60$

From the 1st ancient dwelling.

SNU00-290. sun12

$2020 \pm 60$

From the 8th ancient dwelling.

SNU00-291. sun13

$1810 \pm 100$

From the 13th ancient dwelling.

SNU00-292. sun14

$2100 \pm 40$

From the 28th ancient dwelling.

SNU00-293. sun15

$1860 \pm 70$

From the 1st ancient dwelling. 
Yonggari Series

Yonggari $\left(34^{\circ} 58^{\prime} 06^{\prime \prime} \mathrm{N}, 127^{\circ} 37^{\prime} 00^{\prime \prime} \mathrm{E}\right)$, Kwangyang-si, Jeonnam-do, is a site of ancient dwellings. Samples are charcoals.

SNU00-296. sun18

$1780 \pm 40$

From the 1st ancient dwelling.

SNU00-298. sun20

$1710 \pm 60$

From the 4th ancient dwelling.

SNU00-299. $\operatorname{sun} 21$

$2650 \pm 80$

From the 2nd ancient dwelling. Expected age is 5th century BC.

SNU00-300. sun22

$2550 \pm 70$

From the 1st ancient dwelling. Expected age is 1st century BC.

Songnae Series

Songnae $\left(36^{\circ} 01^{\prime} 36^{\prime \prime} \mathrm{N}, 128^{\circ} 43^{\prime} 18^{\prime \prime} \mathrm{E}\right)$, Seocheon-gun, Gyeonggi-do, is a site of ancient dwellings. Samples are charcoals submitted in 2000 by Jongtae Jeng at the Chungcheng Institute of the Buried Cultural Properties. Expected ages are AD 1st to 4th century.

SNU00-308. CICP1

$1570 \pm 50$

SNU00-309. CICP2

$1620 \pm 50$

From the 5th ancient dwelling.

SNU00-310. S-6-1

$1800 \pm 40$

SNU00-311. CICP4

$1890 \pm 80$

SNU00-313. S-6-5

$1510 \pm 40$

From the 6th ancient dwelling.

SNU00-316. CICP9

$1810 \pm 40$

SNU00-317. CICP10

$2190 \pm 150$

From the 12th ancient dwelling.

SNU00-319. S-17-1

$1550 \pm 40$

SNU00-320. S-17-7

$1550 \pm 70$

From the 17th ancient dwelling.

SNU00-321. S-18-2

$1560 \pm 40$

From the 18th ancient dwelling.

Kian Series

Kian $\left(37^{\circ} 13^{\prime} 36^{\prime \prime} \mathrm{N}, 126^{\circ} 59^{\prime} 18^{\prime \prime} \mathrm{E}\right)$, at the top of Kokum-san, Kian-ri, Hwaseng-gun, Gyeonggi-do, is an ancient dwelling investigated in 2000 by the Chungcheng Institute of the Buried Cultural Properties. The samples are charcoals submitted by Sangnam Kim at SNU and dated from the lowermost cultural layer. Expected ages are 13th-15th century BC, Bronze Age. 
SNU00-359. kogum1

SNU00-360. kogum2

SNU00-362. kogum4

$1960 \pm 60$

Expected age is AD 2nd to 3rd century in the historical age.

$1860 \pm 40$

SNU00-363. kogum5

Expected age is AD 3rd to 4th century, at the beginning of the Bakje Dynasty.

Amur Series

Amur site $\left(51^{\circ} 48^{\prime} 00^{\prime \prime} \mathrm{N}, 140^{\circ} 12^{\prime} 00^{\prime \prime} \mathrm{E}\right), 26 \mathrm{~m}$ asl, Suchu Island, at the end of Amur River, Havarobsk prefecture, Russia, is the 25th ancient dwelling in the area. Samples are charcoals submitted in 2000 by Seodtae Kim, National Institute of Cultural Properties. Expected ages are 30 40 BC.

SNU00-331. suchu1

$2280 \pm 30$

At $32 \mathrm{~cm}$ depth.

SNU00-332. suchu2

$4540 \pm 100$

At $70 \mathrm{~cm}$ depth.

SNU00-333. suchu3

$4950 \pm 30$

At $135 \mathrm{~cm}$ depth.

SNU00-334. suchu4

$4970 \pm 40$

From the 2nd storage hole outside the 25 th dwelling at $30 \mathrm{~cm}$ depth.

SNU00-335. suchu5

$5070 \pm 40$

At $90 \mathrm{~cm}$ depth.

SNU00-336. suchu6

$5140 \pm 100$

SNU00-337. suchu 7

$4740 \pm 70$

At $110 \mathrm{~cm}$ depth.

SNU00-338. suchu8

$4900 \pm 40$

At 95 103 cm depth.

Cheolwon Series

Cheolwon ( $\left.38^{\circ} 11^{\prime} 54^{\prime \prime} \mathrm{N}, 127^{\circ} 15^{\prime} 21^{\prime \prime} \mathrm{E}\right)$, Jangheung-ri, Cheolwon-gun, Gyeonggi-do, is an archaeological site. The samples are charcoals submitted in 2000 by Bogkyu Choi of Gangwon University.

SNU00-380 W70N20

$24,200 \pm 600$

SNU00-381 W80N10

$24,400 \pm 600$

GEOLOGICAL SAMPLES

Sampyung Series

The Sampyung site $\left(35^{\circ} 24^{\prime} 30^{\prime \prime} \mathrm{N}, 129^{\circ} 19^{\prime} 35^{\prime \prime} \mathrm{E}\right)$ was investigated in 1999 by Kiryong Choi. Samples are sediments mainly composed of organic clay and organic silty clay.

SNU00-111. Sampyung1

$4150 \pm 50$

From $152-155 \mathrm{~cm}$ depth. 
SNU00-112. Sampyung2

$1940 \pm 50$

From 92-93 cm depth.

SNU00-113. Sampyung3

$820 \pm 40$

From $40-41 \mathrm{~cm}$ depth.

Gungnamii Series

The Gungnamji site $\left(36^{\circ} 16^{\prime} 00^{\prime \prime} \mathrm{N}, 126^{\circ} 55^{\prime} 00^{\prime \prime} \mathrm{E}\right)$, Buyeo, was investigated in 1999 by Kiryong Choi. Samples are sediments mainly composed of organic clay and organic silty clay.

SNU00-105. Gungnamji 6

$6960 \pm 60$

From 3.44 m depth.

SNU00-106. Gungnamji 12

$7000 \pm 60$

From $3.88 \mathrm{~m}$ depth.

SNU00-107. Gungnamji 32

From $4.82 \mathrm{~m}$ depth.

$\mathbf{2 3 0 0} \pm \mathbf{5 0}$

\section{Bongsandul Series}

The Bongsandul site $\left(35^{\circ} 12^{\prime} 20^{\prime \prime} \mathrm{N}, 126^{\circ} 50^{\prime} 07^{\prime \prime} \mathrm{E}\right)$ was investigated in 1999 by Kiryong Choi. Samples are sediments mainly composed of organic clay and organic silty clay.

SNU00-100. Bongsandul 69

$12,200 \pm 100$

At $3.49 \mathrm{~m}$ depth.

SNU00-101. Bongsandul 48

$11,640 \pm 100$

At depth $2.44 \mathrm{~m}$ depth.

SNU00-102. Bongsandul 31

$10,660 \pm 100$

At $1.59 \mathrm{~m}$ depth.

SNU00-103. Bongsandul 14

$3100 \pm 40$

At $0.74 \mathrm{~m}$ depth.

SNU00-104. Bongsandul 12

At $0.64 \mathrm{~m}$ depth.

Mongtan Series

The Mongtan site $\left(34^{\circ} 52^{\prime} 30^{\prime \prime} \sim 34^{\circ} 54^{\prime} 00^{\prime \prime} \mathrm{N}, 129^{\circ} 28^{\prime} 00^{\prime \prime} \sim 129^{\circ} 30^{\prime} 00^{\prime \prime} \mathrm{E}\right)$, Yengsan River, was investigated in 2000 by Kiryong Choi. Samples are sediments mainly composed of organic clay and organic silty clay.

SNU00-98. Mongtan 9

$2900 \pm 30$

At $10.29 \mathrm{~m}$ depth.

SNU00-99. Mongtan 12

$2330 \pm 30$

At $10.42 \mathrm{~m}$ depth.

Mulgum Series

The Mulgum site $\left(35^{\circ} 18^{\prime} 30^{\prime \prime} \mathrm{N}, 129^{\circ} 00^{\prime} 02^{\prime \prime} \mathrm{E}\right)$, Mulgum-ub, Yangsan-si, Gyeongnam-do, was investigated in 1999. Samples are sediments submitted in 2000 by Sangu U of Daewoo Engineering. 
SNU00-205. SPW-A97-45

$3800 \pm 80$

At $4.5 \mathrm{~cm}$ depth.

SNU00-206. SPW-A97-61

$6250 \pm 80$

At $6.1 \mathrm{~cm}$ depth.

SNU00-207. SPW-A97-77

$6970 \pm 70$

At $7.7 \mathrm{~cm}$ depth.

SNU00-208. SPW-A97-117

$7840 \pm 80$

At $11.7 \mathrm{~cm}$ depth.

SNU00-209. SPW-A97-157

$8220 \pm 80$

At $15.7 \mathrm{~cm}$ depth.

SNU00-210. SPW-A97-205

$8770 \pm 50$

At $20.5 \mathrm{~cm}$ depth.

SNU00-211. SPW-A97-245

$8850 \pm 40$

At $24.5 \mathrm{~cm}$ depth.

SNU00-212. SPW-A97-285

$8900 \pm 200$

At $28.5 \mathrm{~cm}$ depth.

$9660 \pm 120$

SNU00-213. SPW-A97-317

At $31.7 \mathrm{~cm}$ depth.

SNU00-214. SPW-A97-333

$9550 \pm 200$

At $33.3 \mathrm{~cm}$ depth.

Uljin Series

The Uljin site $\left(37^{\circ} 05^{\prime} 54^{\prime \prime} \mathrm{N}, 129^{\circ} 22^{\prime} 42^{\prime \prime} \mathrm{E}\right)$ is a Quaternary deposit at the Uljin atomic power plant, Bugu-ri, Uljin-gun, investigated in 1999. Samples were submitted in 2000 by Taegmo Sim of Korea Atomic Safety Institute.

SNU00-218. Q3-1

$9220 \pm 80$

Wood sample at $2.7 \mathrm{~m}$ asl.

SNU00-219. Q3-2

$6740 \pm 40$

Organic material sample at $3.0 \mathrm{~m}$ asl.

SNU00-220. Q3-3

$6840 \pm 40$

Sediment sample at $3.3 \mathrm{~m}$ asl.

SNU00-221. Q3-4

$1540 \pm 40$

Wood sample at $3.5 \mathrm{~m}$ asl.

SNU00-222. Q3-5

$1600 \pm 50$

Wood sample at $3.5 \mathrm{~m}$ asl.

Silchon Series

The Silchon site $\left(37^{\circ} 21^{\prime} 00^{\prime \prime} \mathrm{N}, 127^{\circ} 19^{\prime} 00^{\prime \prime} \mathrm{E}\right)$, Silchon-ri, Kwangju-gun, Gyeonggi-do, is a deposit in an ancient kiln. Samples are charcoals submitted in 2000 by Juyong Kim of KIGAM. Expected ages are 1500-2000 BP. 
SNU00-352. KJ1

$$
\begin{aligned}
& 1010 \pm 80 \\
& 1000 \pm 40 \\
& 1070 \pm 40
\end{aligned}
$$

SNU00-353. KJ2

SNU00-354. KJ3

\section{Ulsan Series}

The Ulsan site, Ulsan-si, Gyeongnam-do. Samples are organic materials submitted in 2000 by Cahngsik Jeng of KBSI. Expected ages are 25,000-50,000 BP.

SNU00-370. KBSI-1

SNU00-371. KBSI-2

SNU00-373. KBSI-4

SNU00-374. KBSI-5

From Jengja-ri $\left(35^{\circ} 36^{\prime} 54^{\prime \prime} \mathrm{N}, 129^{\circ} 26^{\prime} 42^{\prime \prime} \mathrm{E}\right)$, Ulsan-si.

SNU00-372. KBSI-3

SNU00-375. KBSI-6

SNU00-376. KBSI-7

From Ibsil-ri ( $\left.35^{\circ} 42^{\prime} 12^{\prime \prime} \mathrm{N}, 129^{\circ} 20^{\prime} 18^{\prime \prime} \mathrm{E}\right)$, Ulsan-si.

SNU00-377. KBSI-8

From Siryum-ri $\left(35^{\circ} 39^{\prime} 48^{\prime \prime} \mathrm{N}, 129^{\circ} 27^{\prime} 48^{\prime \prime} \mathrm{N}\right)$, Ulsan-si.

$$
\begin{array}{r}
25,100 \pm 500 \\
12,710 \pm 100 \\
40,100 \pm 2000 \\
40,540 \pm 2000 \\
8340 \pm 100 \\
7850 \pm 100 \\
39,100 \pm 2000
\end{array}
$$

$15,000 \pm 3000$

Chilgok Series

The Chilgok site $\left(35^{\circ} 56^{\prime} 13^{\prime \prime} \mathrm{N}, 128^{\circ} 33^{\prime} 55^{\prime \prime} \mathrm{E}\right)$ is in Chilgok-gun, Gyeongbuk-do. Sediment samples were submitted in 2000 by Kiryong Choi of Ulsan-University.

SNU00-382. chilkog 1

$5580 \pm 80$

SNU00-383. chilkog 7

$5080 \pm 100$

\section{ACKNOWLEDGMENTS}

This work was supported by the Soongsil University Research Fund.

\section{REFERENCES}

Bahk JJ, Chough SK, Jeong KS, Han SJ. 2001. Sedimentary records of paleoenvironmental changes during the last deglaciation in Ulleung Interplain Gap, East Sea (Sea of Japan). Global Planetary Change 28:241-53.

Cheoun MK, Kim JC, Kim IC, Park JH, Kang J. 2001. Pretreatment of iron artifacts at SNU-AMS. Radiocarbon 43(2):217-9.

Kim JC, Lee CH, Kim IC, Park JH, Kang J, Cheoun MK, Kim YD, Moon CB. 2000. A new AMS facility in Korea. Nuclear Instruments and Methods in Physics Research B 172:13-7.

Kim JC, Kim IC, Park JH, Kang J, Cheoun MK. 2001.
Progress of the SNU-AMS facility. Radiocarbon 43(2):163-7.

Kim JC, Youn MY, Kim IC, Park JH, Kang J, Cheoun MK. 2006. Seoul National University Accelerator Mass Spectrometry (SNU-AMS) Radiocarbon Date List I. Radiocarbon, this issue.

Lee C, Kim JC, Park JH, Kim IC, Kang J, Cheoun MK, Choi SY, Kim YD, Moon CB. 2000. Progress in sample preparation system for the Seoul National University AMS facility. Nuclear Instruments and Methods in Physics Research B 172:454-7. 